\title{
INDIGENOUS PRESENCES \\ AND NATIONAL NARRATIVES \\ IN AUSTRALASIAN MUSEUMS
}

This paper takes up the much debated issue of the entry of indigenous artifacts and art into western museums and galleries. I try to see this in a new way by suggesting that the 'decontextualization' involved is not necessarily bad. Putting indigenous and western pieces together does not necessarily impose a universal aesthetic; it may rather draw attention to the incommensurable differences between things, and the history that lies behind such differences.

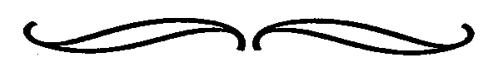

$\mathrm{I}_{\mathrm{s} s}$ discussions of the collection of indigenous people's artifacts that the abstraction of things from ritual activities or everyday uses for sale in the tribal art market, and for storage or display in private collectors' cabinets and public museums, is an operation of decontextualization. And in a sense it surely is: the space of the specimen is often not a mere vacancy or absence, but a nonspace of a singular and radical kind. The unnatural isolation of the displayed object appears to be especially poignant now, given that mainstream audiences have become increasingly aware of the singular values that indigenous objects once had within the fabric of sociality, and still retain from an indigenous perspective: these are not simply tools or art works, but - to use the Maori wordtaonga or inalienable possessions. That understanding is part of a broader reimagining of the histories of Australasian white settler societies. I have picked that awkward and dated geographic label to remind us that in the last quarter of the nineteenth century, when magazines such as The Australasian Sketcher made the term current, both countries were highly conscious of the singular character of their antipodean coloniality, as, in a different way, we are today. National histories are re-presented with the best of intentions, which means that indigenous presences are to be acknowledged. It is the awkward character of that acknowledgement, the ways in which it has worked and not worked, that I explore in this essay, through discussion of two recent exhibitions in national institutions.

Let me begin by going back to decontextualization. The grievous abstraction of indigenous things from indigenous lives is not an operation that 'western' institutions have performed exclusively upon the artifacts of non-western or tribal peoples. Rather, it mirrors what is understood as the key attribute of the modern 
art museum: that is, the displacement of painting and sculpture from religious and aristocratic situations into a space in which things seem defined by an absolute function-lessness, by a similar evacuation of private significance, exchange value, use, and context. Certainly, modernists and contemporary artists may produce particularly for the museum, but our galleries include many works ranging from religious icons to far more recent pieces of so-called craft or decorative art that were made with churches or dining tables rather than display cases in mind. One of my starting points is that this familiar and obvious point - that things in museums are decontextualized - is a bad assumption to begin with, if we are concerned with the meanings and politics of museums and exhibitions. My purpose is not to deny that indigenous artifacts were removed from community uses, and too often stolen; I am not questioning the desirability of repatriating material or otherwise restoring the rights of the groups from whom things were taken. The point is rather that exhibited things are not 'decontextualized', but contextualized in special and powerful ways. Equally importantly, these 'contexts' are not simply social or institutional relations that are external to objects and exhibits: context is projected and defined, to some degree, by content.

Perhaps I can make this clearer by drawing attention to another sort of apparent 'decontextualization' that's very familiar. We often see racks of disembodied clothes and footless shoes, together with many other objects isolated from their functions, in department stores and other shops. Although there are some analogies between the presentation of these commodities and the exhibition of museum specimens, the objects don't seem strangely isolated, because we know that they're being displayed for sale. At other levels, they are there to make class and subcultural distinctions visible in material form; and they could be seen, ideally, to empower consumers by enabling them to imagine themselves variously in the terms suggested by fashionable clothes, books, health foods, or exercise equipment. Arrays of things in the market may thus be abstracted from their most obvious and specific uses, but in fact they do all kinds of things; perhaps most importantly, they teach us not only to desire specific objects, but to invest our efforts of self-definition in that desire.

By the same token, museum objects may be removed from their primary intended uses--the mask floats headlessly, the jug is sadly without wine--but they are nevertheless making themselves useful, busily and perhaps in too many ways. The context is quite different to that of the market, but also similar to it, in the sense that objects have specific meanings, but also more general and implicit effects, in teaching habits of viewing and registers of aesthetic and historical recognition. Exhibitions may present particular bodies of art work, convey information about fields of natural 
history, or specific arguments concerning history and nationhood; their pedagogy may be disguised as entertainment or aesthetic stimulation, but they also convey attitudes toward art, heritage, and technology, ethics of self-refinement, and perceptions of citizenship. With respect to the last, I am not suggesting that either art galleries or museums of natural history have generally been directly concerned with civics education in a narrow sense, but it is obvious that many institutions present the natural environment, histories of military experience, and artistic traditions alike, from a specifically national point of view, encouraging viewers to imagine themselves as Australians or New Zealanders, at once intimately and collectively connected with a natural and cultural heritage, that may be presented in certain terms with certain implications. The museum proffers both particular memories, and a habit of memory that is nationalized; just as it suggests that art works do not cohere merely as the products of individual artists, local milieux, or aesthetic movements, but also, and in more powerful and embracing terms, in national canons. In suggesting that galleries and museums convey habits of collective and national consciousness, I am only restating a point that has become familiar: these institutions, like schools, health services, and censuses, are very much part of the business of government that interested Foucault in his later work.
To appreciate a connection between an individual's aesthetic responses and the efforts of a dispersed modern bureaucracy to socialize a population, is not however to suggest that the museum should now be understood as an instrument of surveillance or discipline in any strong or repressive sense. Museums may make vigorous efforts to define their audiences and present them with certain understandings of history and culture, but their aspirations are often more powerful than their accomplishments. Confusion and contention may be endemic features in public representations of nationality, but there is perhaps a special reason why the rhetoric of many exhibitions is not grasped, or not accepted, by their audiences. Artifacts and art works are objects that can be ordered and captioned and presented in ways that suggest a story, but their material characteristics, and the objectified intelligence that they carry, may undermine or conflict with whatever larger narrative is implied or expressed.

Let me illustrate this briefly through reference to an exhibition that took place in Sydney in $194 \mathrm{I}$, that at the same time gets me back to the theme I have drifted away from, that of the relation between indigenous presences and national narratives in the settler societies of Australia and New Zealand. I mentioned earlier that I wanted to draw attention to the fundamental similarity between the cultural logic of colonization in the two countries, which sometimes simply excluded indigenous people, or denigrated them, yet also 
frequently celebrated indigenous folklore and art, and argued that indigenous reference provided the means for Australians or New Zealanders-writers, composers. artists, and designers - to fashion their own distinctive national cultures that would not simply be impoverished and displaced versions of British tradition. As Margaret Preston put it, with characteristic urgency, "The attention of Australian people must be drawn to the fact that [Aboriginal art] is great art and the foundation of a national culture for this country.' 1 Affirmation and appropriation thus went hand in hand.

Early in 1941, staff at the Australian Museum began to prepare an exhibition of Aboriginal art, together with material that demonstrated its potential as a stimulus for modern china, fabric, architecture,

FIGLRE I

194I Australian Museum exhibition, copyright: The Australian Museum and design; the enthusiasm of arts and crafts practitioners to provide work meant that the show expanded rapidly; with the result that it ended up taking place at the David Jones auditorium, rather than in the more limited space available at the Museum (cover, fig. r). (It's tempting to talk further about the hybrid gallery-department store space, especially because there's been a long tradition of displaying pieces of tribal art in the middle of the fashion departments in that particular store; nothing complements a Perri Cutten suit quite so well. it seems, as a Sepik mask). One might have anticipated that the anthropology curator, Frederick McCarthy, who otherwise wrote extensively on Aboriginal art and archaeology, might have been using the designers' interests as a vehicle for the promotion of the indigenous forms in their own right. Though the Aboriginal work itself only constituted one section

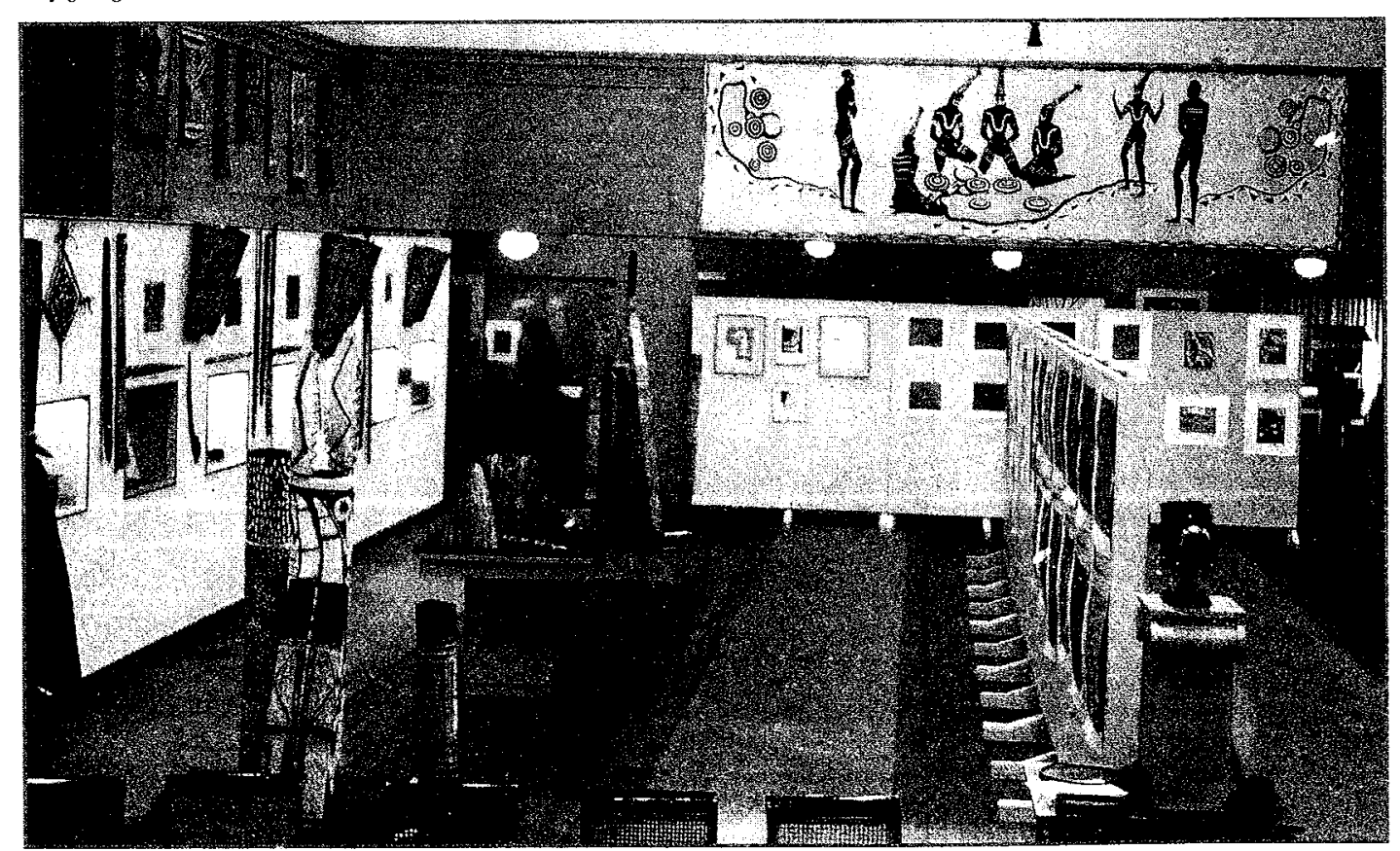


of the exhibition, Museum staff went to considerable lengths to obtain photographs of rock paintings and engravings, and loans of 'weapons, utensils, sacred objects and ornaments' from collections in Melbourne and Adelaide as well as around Sydney. In the event, however, the claims McCarthy made for Aboriginal art in a press release, and in an article in the Museum's magazine, were not only modest but broadly consistent with a primitivist settler-nationalism, that saw Aborigines providing the new nation with a singular prehistory and a set of distinctive motifs that would have a future, not in new expressions of indigenous culture, but in craft produced by white settlers for white settlers.

As he wrote,

It is not contended that aboriginal art equals the abstract and imaginative qualities, or the richness of design, of the art of many other primitive peoples, nor that it approaches the magnificence of the art of the classical civilizations, but it may be claimed that the variety and simplicity of the wide range of motifs and equally numerous techniques... give it a character sufficiently distinctive to identify it with the people, and for this reason it may be said to represent a definite phase of art in Australia. Adapted with intelligence and taste, aboriginal art can make a unique contribution to modern Australian craft work.. In addition, the myths and legends, daily life and art motifs, form an inspiration that may give rise to a national decorative element in Australian architecture. ${ }^{2}$

Given the hesitancy of this assessment of Aboriginal art, it's striking that the critics of the day were ambivalent about the white 'applications', rather than their indigenous sources. One reviewer was circumspect, noting that while the barks showed the aboriginal to be a sensitive artist with a true feeling for design' the paintings 'should be compared with the crude decoration they have inspired on the glassware on view nearby.'3 Another was much more categorical:

Best exhibits by far were the aboriginal bark-paintings... The aboriginal stuff was swell, but all the modern application wasn't. (Glaring examples of the unswell were of the china and glass, and that gay little frieze. All horrible beyond belief....). ${ }^{4}$

And this in a magazine, Ure Smith's National Journal, that had featured these 'applications' a good deal in its own pages. Paradoxically, then, in this case, the effort to assimilate indigenous culture to a distinctively national school of design had underlined the incommensurability of indigenous and settler forms, and hardly sustained the idea that a transition from one to the other, from an aboriginal prehistory to a settler future, represented any kind of cultural progress. In this case, content could be seen to have contradicted context, or at least to have unsettled both the particular agenda of the exhibition and the larger idea of national cultural development that it manifested.

It is, of course, this understanding of national history, from indigenous prehistory through pioneer accomplishment to the expansiveness of antipodean modernity, that is no longer unashamedly 
embraced, either officially or in public perceptions. in Aotearoa New Zealand and Australia. I do not want to go into the similarities and contrasts between indigenous experience and debates about race relations in the two countries, and am merely concerned with the point that a history of indigenous activism, together with shifts in the dominant settler population's attitudes, have prompted governments to take the project of redressing dispossession and discrimination more seriously; over the same period, museums have become theatres for the renegotiation of the national histories that they showcase. (Ideas of nationality have also, of course, been challenged by non-British and non-white migrants, but I do not discuss the significance of their cultural affirmations here).

The Voices exhibition at the Museum of New Zealand, which was opened about the beginning of 1993 , has perhaps been the most unsuccessful of recent attempts to display an inclusive and democratic account of national history in a major public institution. Voices, so named for its emphasis on sound and recorded commentary, is of some importance because it was presented as a kind of trial for approaches that might be implemented in the museum's new harbourside building scheduled to open in Ig98, which will quite appropriately be organized around the understanding of the country as a bicultural nation that has been officially adopted in fits and starts over the last decade. The exhibition followed from much consultation and was certainly well-intentioned. It not only emphasized the Maori presence (figure 3). but also incorporated a good deal of environmental history, and foregrounded women's experiences of events that had conventionally been seen almost exclusively from a male perspective. Unfortunately this was done in too heavyhanded a way, and one journalist--a woman, as it happens--observed rather archly that you could leave the exhibition with the sense that men had played no part at all in the second world war. ${ }^{5}$ Reports in the media suggested that many FIGURE 2

Voices exhibition, courtesy of Museum of New Zealand Te Papa Tongarewa, $r g g 6$

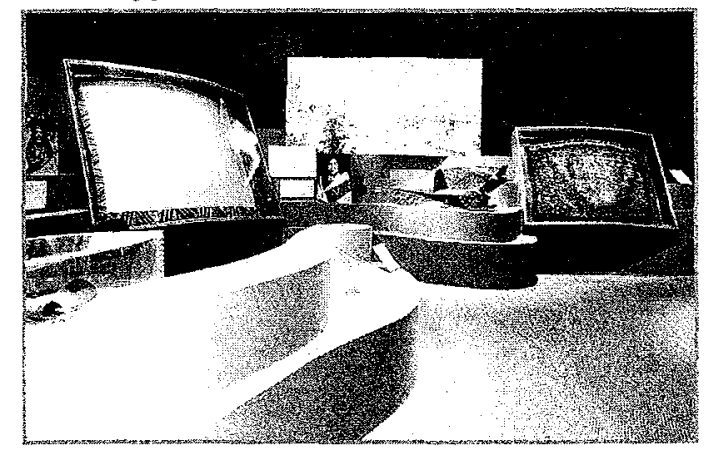

older Pakeha visitors were put out by what they saw as the belittling of the accomplishments of pioneers, who were charged with wholesale deforestation. What was remarkable, though, was that the show appeared to offend absolutely everybody, in the sense that Maori were equally dissatisfied.

The artist and art historian Brett Graham wrote that he'd looked forward eagerly to the exhibition, but found the mock bush 
lifeless and petrified, and other sections 'strangely spiritless'. He was struck by the fact that the story of Polynesian canoe voyaging and colonization-which retains fascination for audiences remote from the Pacific - was 'relegated to a tiny corner' when 'the most dominant and perhaps least successful feature... was a mock galley of a sailing ship, celebrating European arrival' (p. ı/4; figure 4). This was a point that had occurred to me, when I first walked through the exhibit: if curators had really wanted to challenge the 'master narrative that has provided our

FIGURE 3

Voices exhibition, courtesy of Museum of New Zealand Te Papa Tongarewa, 1996

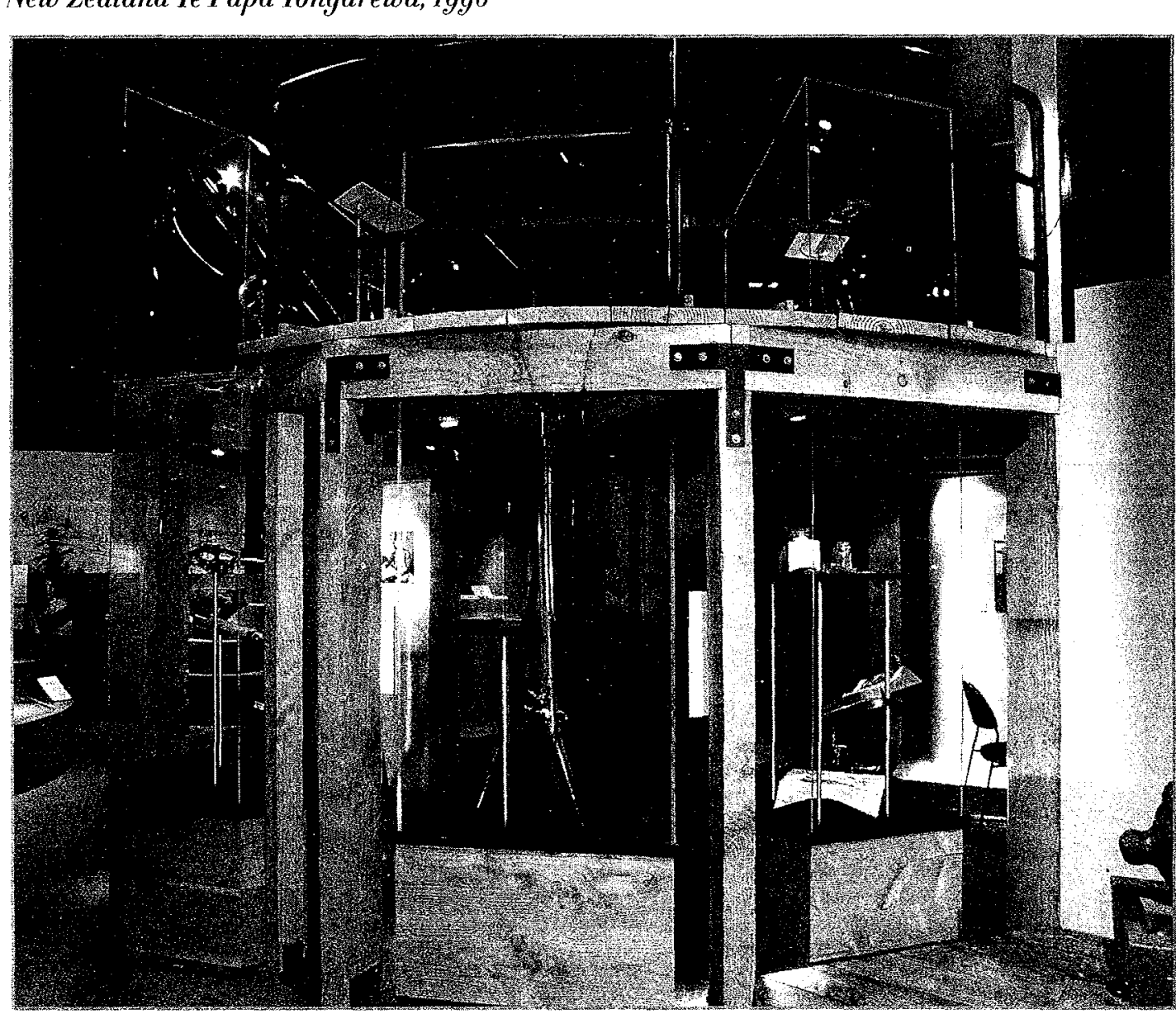

historical perspective up to the present', as one had expressed the aims, sawing up a lot of timber to create an awkward immobile replica of one of Cook's ships seemed a curious way to go about it-though it's perhaps inadvertently interesting, because this is the kind of thing that cargo cult followers in Melanesia are always supposed to have done. Maybe we have more affinities with our Pacific neighbours than we generally imagine.

I suggested earlier that artifacts sometimes overwhelmed the narratives that curators attempted to frame them with, and perhaps this is what occurred here: it was too easy to pass over the texts that 
aimed to engender ambivalence about early discovery and settlement, and simply be overwhelmed by the monumental size of the ship, which seemed to diminish all the indigenous pieces that came before it. It could also be suggested that the installation failed on technical grounds, in the sense that the plurality of voices produced a cacophony. Brett Graham had written that 'the best speakers on the marae choose their words... wisely, economically. Here the voices seemed to scream in competition until I felt uncomfortable, claustrophobic' (p. 14). The value of inclusive plurality, in other words, could be seen to contradict the values of the indigenous tradition that the curators sought to include.

Though the curatorial group was divided evenly between Maori and Pakeha, as between men and women, it is possible also that Maori preferences concerning the presentation of taonga were overlooked. Many conversations have suggested to me that a relatively conventional mode of museum presentation, which remains the approach in other sections of the Museum of New Zealand, and in other institutions in the country, in which artifacts are isolated on walls or pedestals and spot-lit, in fact seems wholly appropriate to many Maori, because the presence and power of their atua and tupuna or ancestors, together with the mana of sacred heirlooms, are emphasized. Placing these things 'in context' by associating them with everyday traditional subsistence activities, by surrounding them with images and words, distracts the viewer from the sheer power of the things themselves, and in that sense may paradoxically effect a more invidious decontextualization than the artifact's isolation in the space of the specimen.

I do not want to speculate further about, or speak for, Maori responses, and instead comment upon what seems to me to have been the most significant underlying flaw of Voices. This is that the values rather than the form of the national narrative were altered; adjustments that seemed to be required by the idea of bicultural nationhood were made, but a certain kind of history remained intact. That history began in a particular natural setting; it had an indigenous opening chapter, that was followed by white discovery, settlement, and twentieth-century experience, which was marked particularly by the great wars. This is the basic story that virtually all of us, I imagine, had at school. Altering the customary assessments of these moments--such that Cook et. al. are disparaged rather than celebrated--does not so much empower Maori, as deprive anybody and everybody of the opportunity to engage with the complexities of eighteenth-century exploration, of the promises and the risks of enlightenment. on the beaches, of the uncertainty around 'discoveries' that were regarded as morally problematic at the time.

More importantly, it fails to identify or articulate an autonomous indigenous history in which nature, prehistory and 
Cook would not, self-evidently, have defined the chapters. By gesturing toward the incorporation of a Maori perspective within a national history, the exhibition forestalled the possibility that incompatible histories might be presented in tension. The laudable idea that everybody should be included seemed to presuppose, in this case, the terms on which people and stories might be included. The point is not that people have different versions of histories, like bosses' and workers' accounts of a strike: some might not have histories that belong to this birth-and-development of a nation model. A Maori counterpoint to a Pakeha history might take the form of an exhibit with no chronological sequence at all, that instead presented ancestors who embodied both past and future in principle, as they both commemorated and anticipated a plethora of more particular accomplishments and transactions. I am not putting this forward as a utopian projection of how a genuinely postcolonial exhibit might look, at some point in the future, but rather suggesting that this is one way in which Maori and others can already respond to exhibits that may otherwise appear to be conventionally ethnological. Almost inadvertently, that old museology empowered the objects that it encased, and created scope for indigenous people to empower themselves by reclaiming the objects-mainly in a symbolic and political sense rather than through physical reappropriationwhich led to the objects being re-empowered in turn. Most visitors to museums in Aotearoa New Zealand are impressed not only by the aesthetic dynamism of the Maori pieces they encounter, but also by the Maori mana that dynamism seems to exemplify. In this case, surely, the content of museums has helped shape their context.

If this is so, the appropriate course of action must be to validate these indigenous perceptions of indigenous objects. This must mean curatorial control and the continuing liaison with indigenous communities that I imagine most in the museum world would now support in principle. The Voices exhibition looks more and more like an extension of the social or popular history strategy from the less privileged groups within white society into the domain of settler-indigenous relations; the strategy comes to pieces in that context because it is not a question of differing perspectives or retelling a history from below, as I already noted, but a more fundamental matter of acknowledging profound cultural differences that extend to constructions of history itself. But if I have argued that these differences can be better addressed by exhibitions that foreground the intelligence of indigenous artifacts themselves-and the kinds of historical imagining those artifacts suggest - that can surely only be a partial solution. It would be partial because indigenous cultures are not, of course, wholly autonomous of the national narratives that white settlers lurch between celebrating and lamenting. How can 
museums and exhibitions mark this interplay, and the conflict of colonization, without according indigenous people a marginal role within an inevitably larger national history, without, in effect, assimilating them?

This brings me to the National Gallery of Australia. The rehang of the Australian galleries there, unveiled in June I994, was generally commended and not much debated. One critique, however, was contained within an otherwise mainly positive review by Humphrey McQueen, whose objections focussed upon the inclusion of mid-nineteenth century Aboriginal artifacts in the rooms containing paintings of the same period (figure 4). McQueen wrote,

The meanings of those Aboriginal pieces are... being expropriated as surely as was the country of the peoples who made them. The juxtaposition of cane baskets with marble busts has the opposite effect of the one intended. Instead of highlighting Aboriginal creativity, the display is an inversion of Batman's offer of beads and blankets in exchange for the Port Phillip district. In the NGA's context, the artefacts are not even tokens, but trinkets.

Much as I respect Humphrey McQueen as a cultural historian, I don't find this assessment of these galleries persuasive. His argument is really that a naive effort to affirm Aboriginal creativity led curators to place baskets with paintings as though they exhibited artistic qualities of the same order; yet this strategy, he suggests, can only obscure the meanings of the Aboriginal pieces, and most partic- ularly the fact that they are not art works in any European sense. He goes on to stress that 'to say that the products of Igth-century Aboriginal communities were not Art is not to devalue their design qualities, but rather to appreciate how different those cultures were from industrial capitalism.'

This strikes me as more valid as a critique of an earlier exhibition of global masterpieces that occupied the large gallery immediately off the NGA's entrance, which included the famous Lake Sentani double figure and the Gallery's paintings by Rubens and Tiepolo. The approach here was similar to that of the Sainsbury Centre at the University of East Anglia, where Jacob Epstein and Francis Bacon rub shoulders with dazzling inlaid shields from the Solomon Islands, and many other African, Oceanic, and native American pieces. All of these works are put forward as works of fine art, and the old evolutionist ranking of cultures is neutralized on a relativist level plain. Most curatorial strategies of course entail both gain and loss, and it is perhaps important to see this affirmation of the products of non-European cultures as retaining some value, especially when 'the western canon' understood in exclusive terms, retains eloquent proponents. But the drawbacks of this relativism are perhaps more conspicuous. It insists on a general equivalence of value while obscuring the particular ground from which various aesthetic expressions emerge. It removes an invidious principle of linear progress 


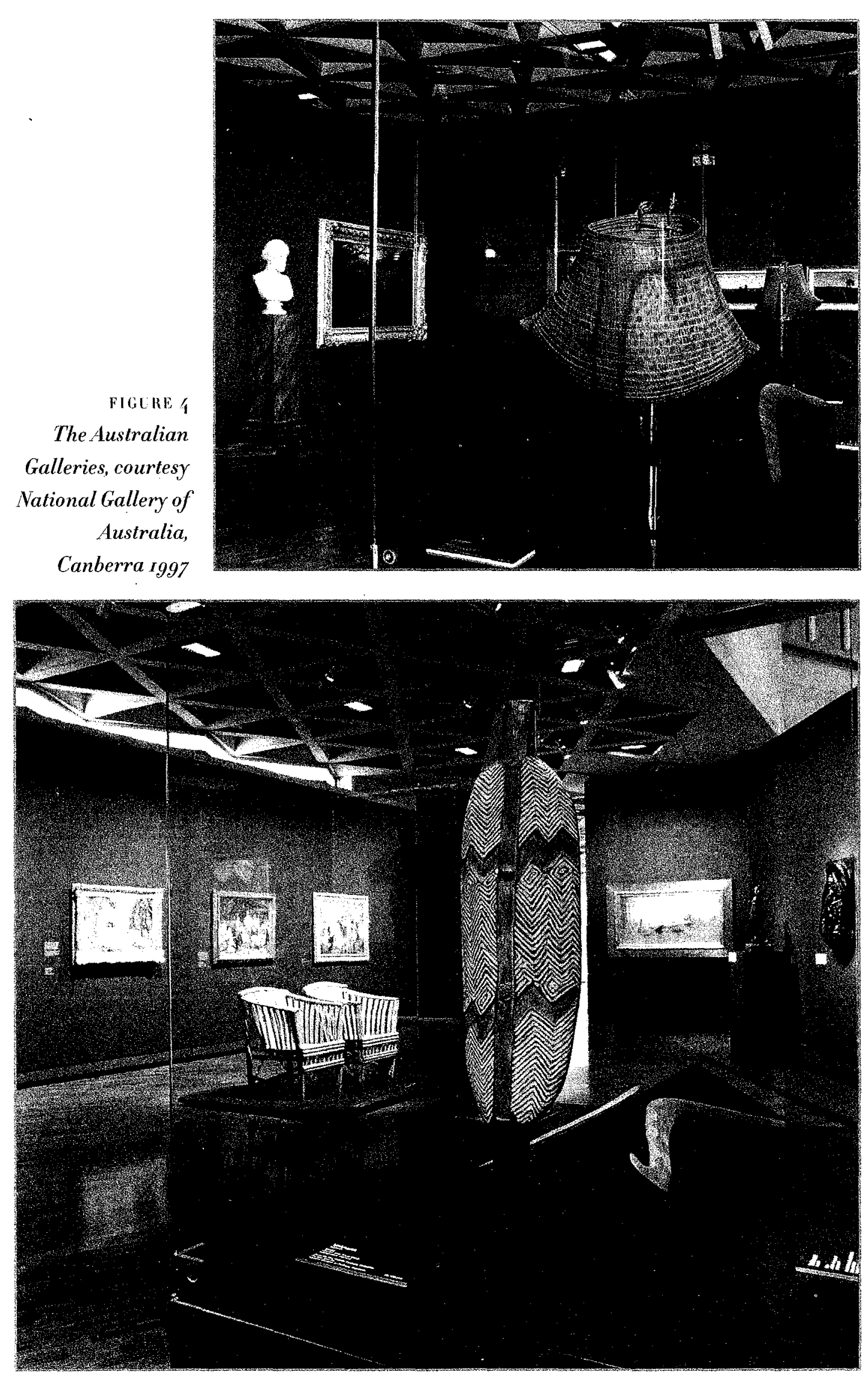


but treats cultures as so many discrete systems, rather than as milieux that have become mutually entangled through exchange and colonization. Hence the overall form of this exhibit conveys no sense of any speciffic relation between the people of Lake Sentani and those of Europe, even though this particular piece is said to have been submerged in a lake to avoid destruction at the hands of missionaries, and though it, like a number of other Oceanic pieces, has been widely reproduced as much because it was once in the collection of a wellknown modernist artist as for its own interest. If facts of this kind, together with the power of the carving itself, make up an uneasy amalgam of meaning, they have no significance in the context of its juxtaposition with Tiepolo or Rubens. Even if we go into the histories of each of these pieces, the gaps are extreme, and we are left simply with a set of powerful yet disconnected works of art.

I find the effect of the Australian galleries to be very different. This is not because the works are more aesthetically proximate. In some ways they are less so: whereas the double Lake Sentani figure can immediately be categorized as a piece of sculpture broadly comparable to western figurations of the human body, the pieces in the case in the centre of the room seem absolutely non-representational; their intricate and powerful patterns can be regarded as the decorated surfaces of utilitarian objects. that strike us immediately as being fundamentally different from the canvases decorated by von Guerard, Chevalier, and others, on the surrounding walls. Surely it would be difficult to find human products more categorically different than these fighting shields and baskets from eastern Australia, and the antipodean expressions of the tradition of romantic landscape painting. Yet in another sense these works are close. We could even say that they are locked together, in a sense in which the Tiepolo and the west Papuan carving are not.

And this is because of a fact that most visitors to those Australian galleries will be conscious of. Von Guerard and others were documenting a process of colonization, and the fact that the accomplishments of pioneers were closely linked with the marginalization of Aboriginal people is sometimes made explicit in their works, that, in a general sense, image the same ground as the artifacts emerge from. Aboriginal and colonial-settler societies were certainly becoming entangled, but it would not be true to say that Europeans and Aborigines shared a history in any meaningful sense. I am not really concerned with the curators' intentions, but I take this exhibition not to fail, in 'highlighting Aboriginal creativity', but to succeed, in underlining an incommensurable difference between the aesthetic practices of colonizers and colonized, which marks wider differences between ways of life, relations to place, and perceptions of history in this period. One body of work depicts the land; the 
other reflects subsistence practice intimately connected with country, and tribal conflict that may have been occasioned by dispute over it, or may have had quite different causes: how can we know? I am suggesting, then, certainly, that the juxtaposition of these pieces allows viewers to engage with the distinctive creativities of the various producers, but more immediately and powerfully compels them to reflect upon the paradox of their difference and their connection.

The implication surely goes beyond any notion that there might be 'two sides' to the story of the settlement of Australia-a narrative of resistance that would balance the narrative of accomplishment. The latter is charted out by the galleries' progression from Cook voyage artists through Glover and Duterrau through to the Heidelberg school and beyond, but there is no sense that Aboriginal experience either simply precedes, or parallels this, in some negative version of the pastoral myth. What we have, rather, are simply a number of implements. Several are intricately patterned, and one, one of the so-called fighting shields, bears a dynamic zigzag. Because of my interest in the optical vigour and complexity of many Pacific art forms, I am inclined to assume that this visual energy complemented, and was taken to exemplify, the energy of the bearer; the fighter's physical prowess, in other words, was augmented by aesthetic brilliance manifest in these kinds of artifacts, and surely in body paint.
The fact that this must be speculation, and that the viewer does not know whether the geometric patterns are actually iconographic and meaningful as well as merely optically compelling, marks the decontextualization that McQueen referred to, yet I would see this abstraction from place and practice as being painfully evident (and in some sense unavoidable for all viewers, rather than apparent only to a sophisticated minority peculiarly mindful of the politics of curatorial presentation). It's worth stressing that this exhibition is one in which the choice of an art historian or even a cultural historian rather than simply a connoisseur is conspicuous: Duterrau's effort to image a grand reconciliation between the Tasmanian Aborigines and the colonial state in the person of George Augustus Robinson is nothing to write home about, as a painting, but is rightly included as an attempt to grapple with the issue of national narrative and indigenous presence that we all know is with us still (figure 5 ). In this context, it is the very decontextualization of the so-called artifacts that speaks loudest.

The implication is not only that indigenous ways of life in southeastern Australia were radically disrupted. It is that no smooth assimilation of this history within national narrative is possible. We are left with a sense that there are other histories and other practices, perhaps in a condition of enduring estrangement, rather than on the point of some happy cultural 


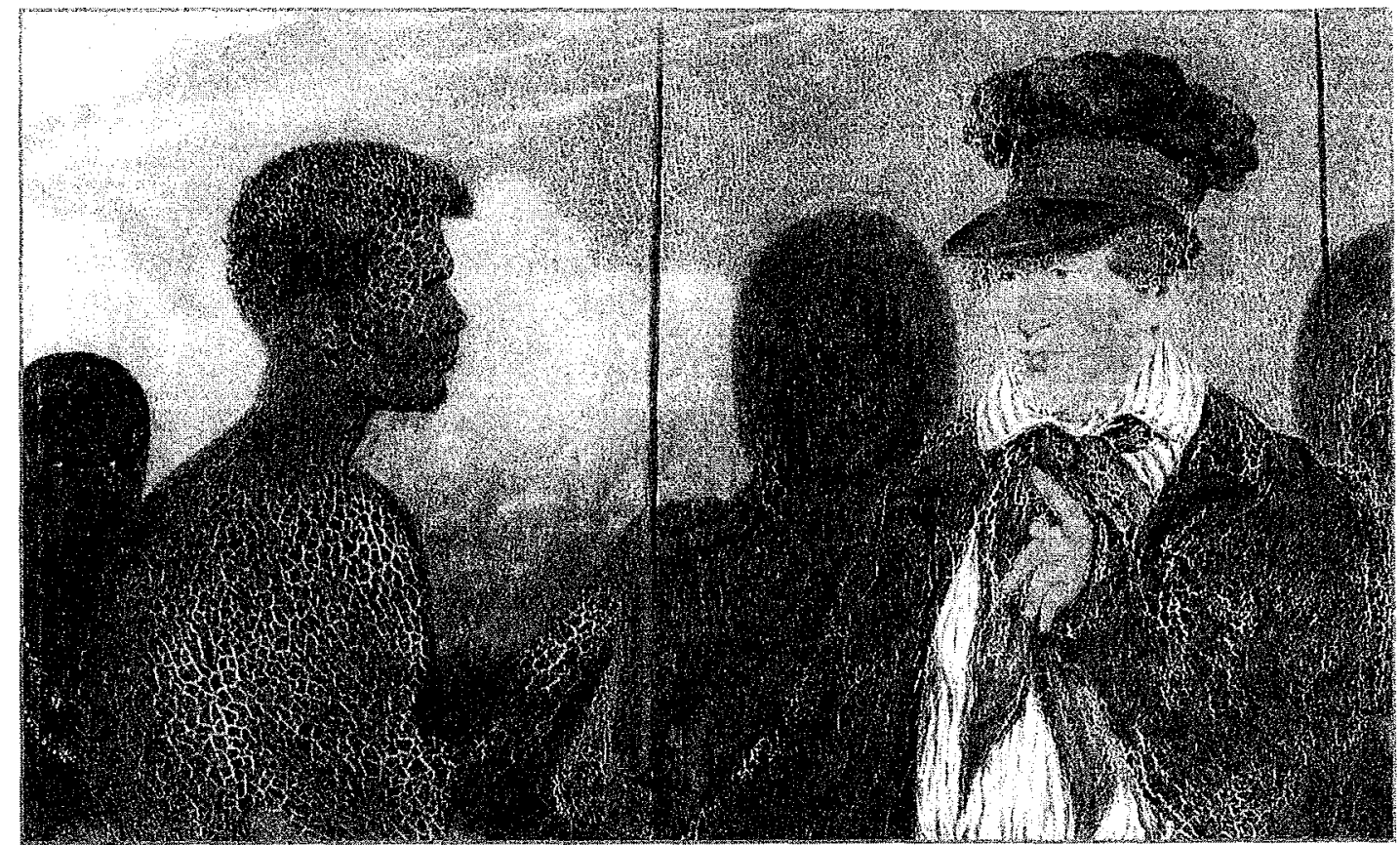

FIGURE 5

Benjamin Duterrau, Mr Robinson's first interview with Timmy, oil on canvas; Collection, National Gallery of-Australia, Canberra.

and political synthesis. In some larger sense, the gallery may aim to image such a synthesis, or at least may aspire to value white and indigenous Australian art equally, and present the stories of both. That is the sort of thing we expect such institutions to do; but in this case the array of content seems in the end to resist any unitary narrative, and if this is so, it is only true and appropriate to the disorderly and contradictory character of history and art history in a cross-cultural, settler-colonial situation.

NICHOLAS THOMAS

Nicholas Thomas is Professor and Director of the Centre for Cross-cultural Research.

\section{REFERENCES}

1 Margaret Preston, 'Aboriginal art', Art in Australia, I June 1941, p. 46.

2 F. D. McCarthy, 'Australian Aboriginal art and its application'. Australian Museum Magazine, I September 194I, Pp. $355^{-5} 6$.

3 'Aboriginal art', Sydney Morning Herald. I2 August 194I.

4 ' 'Abo, art', Australia: National Journal, i September i941, p. 76 .

- Rosemary McLeod, 'The mighty MONZ: artless at heart?' North and South, October I994. pp. 7o-8o.

6 Breft Graham, 'An infinity of roices', Midwest 3. I993. p. I3.

? Humphrer McQueen, 'Capital outlook for home-grown art'. The Weekend Australian, I8 June 1994. p. 25. 